DE DE GRUYTER OPEN

\section{Research Article}

(C) 2017 Paul Kombo.

This is an open access article licensed under the Creative Commons Attribution-NonCommercial-NoDerivs License (http://creativecommons.org/licenses/by-nc-nd/3.0/).

\title{
Radicalization as a Functional Aspect of Crime
}

\section{Paul Kombo}

Machakos University

Doi: 10.1515/mjss-2017-0053

\begin{abstract}
Radicalization into extremism and terrorism is a controversial topic amongst scholars on the approaches used to understand the phenomenon. This paper examine some theories on the subject and the debate raging amongst scholars with regard to the differing models and approaches. The key theories examined in respect to radicalization include the theological model, the psychological approach, vulnerability explanations, discrimination/alienation models and political explanations.
\end{abstract}

Keywords: Security, Crime, Radicalization, Extremism

\section{Introduction}

Some models of crime causation suggest that crime engagement is triggered primarily by factors to do with strain or pressure that push people into crime and or is learned as part of socialization (Mushanga, 2014; Whitaker and Pollard, 2013). Theories on causes of crime agree that the factors that lead to a person engaging in crime are many and include poverty, unemployment, parental neglect, peer pressure and lifestyles, among others (Weatherburn, 2002; Edmiston, 2015; Patterson, 2013). It is also agreed that these factors become more effective in the causation of this behavior when they combine and operate together. However, no one single factor alone has been empirically shown to cause people to engage in criminality (Patterson, 2013). In order to explain the phenomenon, scholars have formulated a general strain theory suggesting that crime is caused by strain or pressure on the offender (Agnew, 2016; Iratzoqui, 2015; Day et al, 2012). Earlier, Gottfredson and Hisrchi (1990), in their "A General Theory on Crime', argued that self-control is central to the causation of crime since this is learned in early parental socialization of children into self-control by punishing deviant acts which result in avoidance of deviant behaviours later in life. This idea of self-control as a general concept around which all forms of crime can be understood is also supported by several other researchers (Akers, 1991; Polakowski, 1994). To others, factors such as neighbourhoods, poverty, poor parenting, peer pressure as well as violence witnessed within the family and in the community are to blame for crime (Weatherburn, 2001; Noguera, 2003).

Lately, some scholars have argued that aggression exhibited by young people is caused by multiple factors among which are peers, family, schools and neighbourhood circumstances (LingYin et al, 2016). Effects of these factors lead to low self-esteem and perceptions of being insecure which when internalized and externalized by the victim result in negative behaviours (Kim and Lo, 2015; Evans et al, 2012). The social disorganization theory posits that socio-economic disadvantages and instability can reduce the formation of norms and values in a community that act as social control and protection against deviance (Patterson et al, 2015; Ling-Yin et al, 2016).

The situational action theory of crime causation (SATCC) (Wikstron, 2009 and Wikstron et al, 2010) suggests that morality is linked to delinquent behavior (Doering and Baier, 2016) since people with high moral standards and values are less likely to commit violent crime. Such people 
possess empathy that makes them sympathetic to would-be victim. The theory has some similarities with the general theory of crime in that it acknowledges early socialization in morality. Forde and Kennedy (2016), while agreeing that Gottfredson and Hirschi's General Theory of Crime (1994), offered many insights into the likely causes of criminal behavior, suggested that it failed to acknowledge that past experience, lifestyle and learning influenced propensity to commit crime. They also faulted the general theory for not clearly showing the link between propensity and opportunity to commit crime. Exposure to violence in neighborhoods, Bowen and Bowen (1999) argued, influences the emotional and behavioural characteristics of students towards criminality. The Situational Action Theory is useful for examining underlying psychological patterns behind actions of committing crime in that they explain what goes on in the mind of a person in deciding whether or not to commit crime.

The routine activity theory has identified neighbourhoods as an important factor that contributes to crime despite being initially not recognized as such (Mustaine et al, 2012). Characteristics of neighbourhoods that have been researched include poverty, unemployment, schools, abandoned buildings as well as poor street lighting since they are related to victimization (Skogan, 1990; Mustaine and Tewksbury, 1998a). These neighbourhood characteristics offer opportunities for offenders and victims to be present in one area thus increasing potential victimization risks (Mustaine et al, 2012). Other research posits that neighborhoods in which young people grow up in also influence their developmental directions later in life. For example, according to Wilson's (1975) theory of neighborhood effects, adolescents growing up in disadvantaged neighborhoods are likely to develop deviant values and behaviours (Wilson, 2013; Stewart and Stewart, 2007). This model helps in explaining the factors that can drive a person to engage in deviant behaviour.

\section{Research Methodology}

This study was conducted in two public universities namely, Machakos University (MU) and South Eastern Kenya University (SEKU). Two approaches were used in this study to examine radicalisation studies (Creswell, 2013;). On the one hand, are models defining radicalisation as a process using theological and vulnerability models claimed to be used to justify counterterrorism measures. The second model comprises critiques who have questioned counterterrorism approaches based on these factors. Mainly using the qualitative approach of data collection, the study used a questionnaire with carefully formulated questions to elicit rich information for analysis (Ritchie et al, 2013; Kothari, 2005).

\section{Theories of Crime Causation}

Gottfredson and Hirschi (1990) define crime as 'acts of force or fraud undertaken in pursuit of selfinterest". Researchers have categorised crime theories according to the approaches used for studying the issue. A theory is described by Akers (2013) as a set of related statements that explain how two or more events or factors are connected to each other. For example some have described types of crime theories according to the individual model which include factors like personal decision to commit a crime as a result of an opportunity and the expected benefit and possible cost of apprehension. Crime causes are also studied using sociological explanations which comprise conditions, culture, and economic factors (Gabor, 2010). Social disorganisation theories posit that poor neighbourhoods are potential environments where delinquency can thrive due to poverty (Edmiston, 2015).

The neighbourhood model views crime causation as comprising several strands notably how the influence of peers, family members, social organisation surrounding the individual influence and shape criminal behaviour in the youth (Livingston et al, 2014). The theory also explains the effect of how the involvement of siblings and parents in crime can influence an individual to participate in violence and crime (Bannister et al, 2010). Wikstrom et al and others (Wikstron, 2012; 2010; Maimon and Browning, 2010, Miller, 2013)) described situational characteristics that provide the circumstances for offending by adolescents as consisting of presence of peers, absence of adults, 
involvement in unsupervised activities, presence in a public place and use of alcohol or drugs. These models have some common characteristics to the routine activities theory that argues that crime occurs where there is convergence of potential offenders and suitable targets without guardians (Felson, 1979). A neighbourhood where there are many young adults and operation of many bars are considered suitable places for criminal behaviour since large numbers of potential offenders and targets are present at the same place and time (Raleigh and Galster, 2012). This explanation is consistent with the life-style exposure theory that suggests that different life-styles can result in differences in victimisation depending on the different places, times and proximity to offenders (Miethe and Meier, 1994).

These theories fit in well with the rational choice theory which holds that an offender makes rational choices when committing crime, a model that has been used by law enforcement and security organisations to formulate control measures utilised to make it hard for criminals to access or penetrate a target, a method called target hardening. Crime explanations offered by proponents of the routine activities theories, first developed by Felson and Clarke (1978), do not focus on explanations of crime being caused by conditions such as poverty, unemployment and family dysfunction but instead argue that crime is present in everyday situations since offenders are average people. Felon's routine activity theory proposed that crime occurs when offenders come across valuable targets at a place and time without guardians to protect (Rock, 2009).

Other explanations such as the Social Disorganisation, Social Capital and Collective Efficacy theories have been grouped under the Social Integration theories since they explain aspects of neighbourhood and the community in relation to crime occurrence (Gorman et al (2013). Researchers using these approaches have elucidated their conceptualisations through the Routine Activities and Crime Potential Theories both of which place importance of places where crime can occur and interactions between potential offenders and potential victims as the common ingredients and how people make use of the spaces around them. Other criminology research focuses on the kinds of pressures that push people to commit crime, and the socialising especially of children to learn criminal behaviour or to refrain from it (Agnew, 2016).

'A General Theory of Crime' by Gottfredson and Hisrchi (1994) argued that people with low self-esteem tended to be more predisposed to behaviours of impulsiveness and insensitivity towards others and therefore likely to commit crime. Forde and Kennedy (2006), in their study, found that while Gottfredson and Hirschi's general theory offered insights as to the proneness to commit crime, it did not explain whether childhood socialisation could affect propensity to commit crime. They suggested that the way to remedy this weakness is to change the variables of selfcontrol and opportunity to commit crime and to improve anger management. Agnew (2006) argues that the behavioural approach is explained by three main theories namely: the strain theoriesfocusing on the strains and stressors that drive or force people into criminal behaviour as a coping mechanism, the social learning theories-people acquire criminal behaviours because they learned them early in life and the control theories-focusing on the kinds of controls that refrain people from crime (Agnew and Brezina, 2015; Akers, 2009).

Criticisms of these theories are that they do not explain all the variations in crime given that most people do not respond to pressures and attractions for crime even though they may have low self-esteem (Agnew, 2016). The perceived deficiencies in these theories have given rise to several lines of research, for example, resilience research which holds that factors like temperament and self-esteem influence response to pressures and attractions (Losel and Bender, 2003; Rutter, 2006). Other approaches include the psychological research which describes how traits such as negative emotions, hostile interpretation of others intentions, and the biological research concerned with genetic factors that influence response to criminal pressures and attractions (Beaver et al, 2015). Despite the criticisms of these early theoretical models, they serve as good starting points for understanding some of the behaviours that can lead to criminal acts. With this illumination of the issues, more research has been constructed based on their building blocks which promise to show a clearer picture of causes of crime. 


\section{Theory of Crime Resistance and Susceptibility}

To deal with the noted deficiencies in the three major theories on crime, the Theory of Crime Resistance and Susceptibility (TCRS) has been advanced. The theory, proposed by Agnew (2016), looks at four factors it regards as playing a key role in determining resistance and susceptibility to criminogenic events and conditions: These include negative reaction to events, that is, negative interpretation of events and conditions as bad and unjust may make one angry and inclined to be aggressive or rebellious. This is influenced by factors such as anger, hostile attribution of intention on others, sensitivity to injustice, among others (Simons et al, 2011; Losel and Bender, 2003; Bondu and Elsner, 2015). People can learn to be negative about issues which they regard as unfair or unjust or learn to react aggressively to events they interpret as a slight on their masculinity or other vanity because they believe that the best way to deal with them is to be aggressive and rebellious (Felson et al, 2012).

The theory further posits that materialistic and pleasure seeking that is not earned through hard work and sacrifice, consisting of material possessions, power, prestige, thrills, excitement and physical pleasure can tempt someone to engage in criminal acts (Ksendzova et al, 2015; Taylor and Eitle, 2015).The other element of the theory posits that social support and self-efficacy that provides encouragement, skills and resources for coping with strains can significantly counter the mental need for resorting to criminal behaviours (Babdura, 2012; Brezina, Tekin, and Topalli, 2009). Some people are more sensitive than others to factors such as criminal or prosocial influences based on whether they are amongst high or low criminogenic environments which can account for engaging or not engaging in criminal acts. Some controversial research claims that this trait of high sensitivity has genetic origins (van ljzendoorn et al, 2012). Other researchers, however, see it as influenced by factors such as social learning, pressure to conform to a new culture, and a strong desire for social acceptance (Hughes and Short, 2014). The explanations given by the Theory of Crime Resistance and Susceptibility offers insights into the kinds of behaviours and emotions that people can experience or learn or be exposed to which can lead to engaging in criminal acts. This is important for understanding why some people tend to involve themselves more readily to crime than others.

Another way to understand crime and victimization is by using the routine activity theory which has as its central argument that criminal activity occurs when offenders and victims intersect in the absence of guardians (Mustaine et al, 2012, citing Lauritsen et al, 1991). The theory, though criticized for failing to examine the important roles of both offenders and victims, holds that people who spent much time close to each other are often involved in offending and victimization amongst themselves. This can be applied to a married couple or to an environment such as a university campus where a large population of students spent much time close together, hence bringing potentially large concentrations of offenders and victims to one place, thus increasing the incidents of offending and victimization (Fisher et al, 1998). This theory can be applied to design measures for controlling behaviours in places where many people interact as a crime prevention method.

\section{Exposure to Violence and Environmental Influence}

Family and parenting factors have been shown to shape children's propensity to anti-social behaviour. Children who are exposed to violence within their own homes or witness the same in the community where they live are more likely to acquire similar behaviours later in life (Delisi and Vaughn, 2016; Margolin and Gordis, 2000). This exposure to violence shapes their views of the world as a place where you have to use violent means to achieve what you want in life. Secondly, such children learn to use violence as a defence mechanism (Kim and Lo, 2015). Theoretical models have been formulated to show that aggressive children and adolescents are more likely to engage in other forms of deviant behaviour which is linked to their neighbourhoods (Moore et al, 2014). A framework showing this relationship was formulated by Jencks and Mayer (1990) comprising five factors namely availability of resources, community social organisation, deviant neighbours and peers, competition for resources and poverty to explain the link between deviant behaviour and neighbourhoods. A similar framework consisting of three mechanisms was 
formulated by Leventhal and Brooks-Gunn (2000) to demonstrate how these factors influence crime in neighbourhoods. These factors are the quality of relationships and parental and community support, the norms and collective efficacy to control behaviour and availability, quality, and accessibility of health care, education, recreation, employment opportunities. This can be applied to create policies for mitigating such adverse situations.

Unprovoked aggression could be a result of earlier victimisation in which the perpetrator is involved in revictimisation behaviour. One of the ways to explain this behaviour is through the Social Information Processing Theory (SIPT) that posits that adolescents exposed to violence at an early age are likely to view ambiguous situations as threatening by exhibiting aggression (Quille and Grffin, 2009). Some researchers have focused on personal characteristics, environmental and communal factors to explain origins of crime. Such researchers have held as their focus personal characteristics as poverty, unemployment, overcrowding and neighbourhood structures as important for understanding causes of crime (Mustaine and Tewksbry, 2000). These two posit that few researchers have tried to identify any overlap between offending and victimisation. They have argued, using the routine activity theory, that the likelihood of crime increases when there is frequent contact between offenders and victims and have advanced that a neighbourhood would be such a contact area.

The Situational Action Theory of Crime Causation (STCC) (Doering and Baier, 2016, citing Wikstrom, 2009; Wikstrom et al, 2010), links criminal behaviour and delinquency to morality. The theory suggests that criminality is caused by bad morals and that people commit crimes as a choice from other alternatives. Therefore, it is argued, moral standards of a person determine their likelihood of engaging in crime or not (Doering and Baier, 2016. The situational and environmental approaches shed light into factors and situations that contribute to crime mentality and are important in helping us to understand the various factors and influences that are underlying some forms of crimes. The theory has benefit for addressing learning processes to include aspects of moral training.

\section{Social Disorganization Theory}

The theory has its origins in the study on criminality in Chicago City in the early 1900s which showed disparities in crime rates in certain of its neighbourhoods. Social organization is said to exist when there is agreement on common norms and values, cohesion among residents and regular interaction amongst residents. (Kubrin and Wo, 2016). When these characteristics are present, they ensure informal control which is important for solving community problems including crime (Shaw and McKay, 1969). According to the social disorganization theory, socially disorganized neighbourhoods have less informal control and are likely to experience increased crime with characteristics such as poverty, unemployment and family disruption. Social ties and informal control have been shown to be important factors for understanding social disorganization but lately additional dimensions have been included namely collective efficacy, social capital and social networks (Kubrin \& Wo, 2016). Collective efficacy comprises the willingness and trust to intervene on behalf of the common good as a way of achieving social control for preventing crime in the neighbourhood (Sampson and Groves, 1989). The other aspects of collective efficacy are cohesion and mutual trust and sharing common goals for the purpose of addressing community issues together. Sampson and Groves showed that these were prerequisites for achieving lowered crime rates in the neighbourhood.

The social disorganization theory sheds light into the ways in which communities exist as social units capable of regulating their affairs including crime prevention through social control. This can help policy makers to identify ways in which governments and other bodies can intervene in ways aimed at boosting the capacities of such communities to be self-independent as a method of lowering crime.

\section{Theorizing Radicalisation}

Radicalisation issue has received divergent views from criminology and securitisation researchers. 
Some have argued that radicalisation is caused by grievances and vulnerabilities (Borum, 2011; Wiktorowicz, 2005; Bizina and Gray, 2014; Brown and Saeed, 2015), while others suggest radicalisation is driven by the Jihadi-Salafi ideology that seeks to purify Islam (Blanchard, 2007). The opposing view sees the explanation of radicalisation from theological and ethnic approaches as being problematic in that the meaning of the term radicalisation is unclear (Coppock and McGovern, 2014; Heath-Kelly, 2013; Kundnani, 2015; Hussain and Bagguley, 2012). The radicalisation debate is riven with controversy where one school argues it is a process that progresses through stages whilethe other viewpoint sees these explanations of a radicalisation process approach as a narrative to justify securitisation of some communities and religions (Sageman, 2006).

Theoretical approaches about how young people get inducted into deviant and criminal behaviours may not give a good understanding of how radicalisation into extremism, which can manifest itself in terrorism, occurs (Christmann, 2012). Theoretical models of radicalisation suggest that grievances and vulnerabilities are transformed into hatred which can materialise in some people through committing terrorist acts (Borum, 2011). Some researchers of modern terrorism claim that radicalisation is driven by the Jihadi-Salafi ideology which seeks to purify Islam of western culture (Blanchard, 2007). Definitions of radicalization among security agencies is problematic because of the lack of clarity in the meaning of the term which can allow for differing interpretations with the potential for widening of its applicability by government agencies (Coppock and McGovern, 2014). The issues of contention revolve around approaches that focus on psychological and social factors that some scholars attribute as the main contributors to extremism while ignoring or paying meagre attention to other factors such as political acts and policies of Western countries that are claimed by others as the root causes of the problem (Sageman, 2008).

\section{Stages of Radicalisation Model}

Theories on radicalisation, the process through which some researchers claim a person is introduced into an extremist mind-set, advance the idea of stages leading to eventual acceptance into terrorist activity. Wiktorowicz (2005) uses the four stage model of radicalisation namely: cognitive opening, religious seeking, frame alignment, and socialisation (King and Taylor, 2011). These stages are triggered in sequential order starting with the cognitive opening that could be some crisis in one's life like a job loss or discrimination experience or victimisation or impressions gained from discussion with a member /s of Islamic extremists. The second stage is the religious seeking which is precipitated by the first stage, setting the stage for inculcating worldviews promoted by the extremist group through debate and discussions. At this stage, the target is comparing his own views with those promoted by the extremist group, a step where there is frame alignment at and differing to the group expertise of the group. The last stage is when the target has internalised group ideology resulting in his/her individual identity being reformulated. At this point the person officially joins the extremist group.

\section{The Staircase Model of Radicalisation}

Moghaddam's (2005) staircase to terrorism model, which is similar to the stages model, progresses from the first floor through six stages to the top at which the person in question may or may not progress to the final stage of accepting involvement into terrorism (King and Taylor, 2011). Explaining his theory, Moghaddam proposes that people who experience deprivation will be motivated to try and improve their lot through social mobility and procedural justice. If the group views the system to be unfair or that it does not promote social justice, they may feel discontented and move to the next stair. At the next stair, people start blaming the perceived cause of their problems, a state, an individual or other entity. Some of the group members may now resort to radical measures to redress their grievances with disparate factions among the group starting to put aside differences for the good of the bigger group. Those who progress to the fifth stair, which is the last floor, are the committed ones ready to commit terrorist attacks. 


\section{Conclusion}

The two perspectives of the processes of radicalisation help us to understand how people react to recruitment efforts by terror groups and hence address the underlying issues that could convince a potential recruit to accept to join such a group. It helps policy makers to identify the types of policies that can trigger extreme reactions in certain groups among some communities so that such policies can be moderated to exclude the negative approaches.

\section{References}

Agnew, R. (2016). A Theory of Crime Resistance and Susceptibility. Criminology, 54(2), 181-211.

Akers, R. L. (1991). Self-control as a general theory of crime. Journal of Quantitative Criminology, 7(2), 201211.

Bizina, M., \& Gray, D. H. (2014). Radicalization of Youth as a Growing Concern for Counter-Terrorism Policy. Global Security Studies, 5(1), 72-79.

Borum, R. (2011). Radicalization into violent extremism II: A review of conceptual models and empirical research. Journal of Strategic Security,4(4), 37.

Boutwell, B. B., Barnes, J. C., Beaver, K. M., Haynes, R. D., Nedelec, J. L., \& Gibson, C. L. (2015). A unified crime theory: The evolutionary taxonomy.Aggression and violent behavior, 25, 343-353.

Brown, K. E., \& Saeed, T. (2015). Radicalization and counter-radicalization at British universities: Muslim encounters and alternatives. Ethnic and Racial Studies, 38(11), 1952-1968.

Brezina, T., \& Topalli, V. (2012). Criminal self-efficacy exploring the correlates and consequences of a "successful criminal" identity. Criminal Justice and Behavior, 39(8), 1042-1062.

Christmann, K. (2012). Preventing Religious Radicalisation and Violent Extremism: a systematic review of the research evidence.

Cohen, L. E., \& Felson, M. (1979). Social change and crime rate trends: A routine activity approach. American sociological review, 588-608.

Commission for University Education, (2016).

Cooley-Strickland, M., Quille, T. J., Griffin, R. S., Stuart, E. A., Bradshaw, C. P., \& Furr-Holden, D. (2009). Community violence and youth: Affect, behavior, substance use, and academics. Clinical child and family psychology review, 12(2), 127-156.

Coppock, V., \& McGovern, M. (2014). 'Dangerous Minds?' Deconstructing Counter-Terrorism Discourse, Radicalisation and the 'Psychological Vulnerability of Muslim Children and Young People in Britain'. Children \& Society, 28(3), 242-256.

Creswell, J. W. (2013). Qualitative inquiry and research design: Choosing among five approaches. Sage.

Crone, M. (2016). Radicalization revisited: violence, politics and the skills of the body. International Affairs, 92(3), 587-604.

Edmiston, K. D. (2015). Property Conditions and Neighborhood Crime. Available at SSRN 2567835.

Edwards, G. (2014). Social movements and protest. Cambridge University Press.

Felson, M. (1995). Those who discourage crime. Crime and place, 4, 53-66.

Fisher, B. S., \& Sloan, J. J. (2013). Campus Crime: Legal, Social, and Policy Perspectives. Charles C Thomas Publisher.

Gottfredson, M. R., \& Hirschi, T. (1990). A general theory of crime. Stanford University Press.

Guardian/ICM Poll (2004): Radicalisation into terrorism

Fisher, B. S., Sloan, J. J., Cullen, F. T., \& Lu, C. (1998). Crime in the ivory tower: The level and sources of student victimization. Criminology, 36(3), 671-710.

Hafez, M., \& Mullins, C. (2015). The radicalization puzzle: a theoretical synthesis of empirical approaches to home-grown extremism. Studies in Conflict \& Terrorism.

Heath-Kelly, C. (2013). Counter-terrorism and the counterfactual: Producing the 'radicalisation discourse' and the UK PREVENT strategy. The British journal of politics and international relations, 15(3), 394-415.

Hussain, Y and Bagguley, P, (2012). Securitised citizens: Islamaphobia, racism and the 7/7 London bombings. The Sociological Review, 60 (4). 715-734 (20). ISSN 0038-0261

Kruglanski, A. W., Gelfand, M. J., Bélanger, J. J., Sheveland, A., Hetiarachchi, M., \& Gunaratna, R. (2014). The psychology of radicalization and deradicalization: How significance quest impacts violent extremism.Political Psychology, 35(S1), 69-93.

Kubrin, C. E., \& Wo, J. C. (2016). Social Disorganization Theory's Greatest Challenge: Linking Structural Characteristics to Crime in Socially Disorganized Communities.

Kundnani, A. (2015). Radicalisation: the journey of a concept. Race \& Class, 54(2), 3-25. 
Ksendzova, M., lyer, R., Hill, G., Wojcik, S. P., \& Howell, R. T. (2015). The portrait of a hedonist: The personality and ethics behind the value and maladaptive pursuit of pleasure. Personality and Individual Differences, 79, 68-74.

Lauritsen, J. L., Sampson, R. J., \& Laub, J. H. (1991). The link between offending and victimization among adolescents. Criminology, 29(2), 265-292.

Livingston, M., Galster, G., Kearns, A., \& Bannister, J. (2014). Criminal neighbourhoods: does the density of prior offenders in an area encourage others to commit crime? Environment and Planning A, 46(10), 24692488.

Lösel, F., \& Bender, D. (2014). Aggressive, delinquent, and violent outcomes of school bullying: Do family and individual factors have a protective function? Journal of school violence, 13(1), 59-79.

Maimon, D., \& Browning, C. R. (2010). Unstructured socializing, collective efficacy, and violent behavior among urban youth. Criminology, 48(2), 443-474.

McCauley, C. (2012). Testing theories of radicalization in polls of US Muslims. Analyses of Social Issues and Public Policy, 12(1), 296-311.

McNeeley, S. (2014). Lifestyle-routine activities and crime events. Journal of Contemporary Criminal Justice, 1043986214552607.

Moghaddam, F. M. (2005). The staircase to terrorism: a psychological exploration. American Psychologist, 60(2), 161.

Mushanga, T. M. (2014). Crime and deviance: An introduction to criminology. Law Africa Publishing Ltd.

Ritchie, J., Lewis, J., Nicholls, C. M., \& Ormston, R. (Eds.). (2013). Qualitative research practice: A guide for social science students and researchers. Sage.

Skogan, W. (1990). Disorder and decline: Crime and the spiral of decay in American cities.

Yang, M. S. (2006). Understanding the effectiveness of moral mediation through theories of moral reasoning (Doctoral dissertation, The Ohio State University).

Vaughn, M. G., Salas-Wright, C. P., DeLisi, M., \& Maynard, B. R. (2013). Violence and externalizing behavior among youth in the United States: Is there a severe 5\%? Youth Violence and Juvenile Justice, 1541204013478973.

Webster, C. (2014). Impact of Poverty on Crime.

Wiktorowicz, Q. (2005). Radical Islam rising: Muslim extremism in the West. Rowman \& Littlefield Publishers. 